Article

\title{
Go Greener, Less Risk: Access to Nature Is Associated with Lower Risk Taking in Different Domains during the COVID-19 Lockdown
}

\author{
Angelo Panno ${ }^{1, *}++^{(D}$, Annalisa Theodorou ${ }^{2, *}++^{-}$, Giuseppe Alessio Carbone ${ }^{1}$, Evelina De Longis ${ }^{3}$, \\ Chiara Massullo $^{1}(\mathbb{D})$, Gianluca Cepale ${ }^{3} \mathbb{D}$, Giuseppe Carrus ${ }^{2}$, Claudio Imperatori ${ }^{1}$ (D) and Giovanni Sanesi ${ }^{4} \mathbb{D}$
}

check for updates

Citation: Panno, A.; Theodorou, A.; Carbone, G.A.; De Longis, E.; Massullo, C.; Cepale, G.; Carrus, G.; Imperatori, C.; Sanesi, G. Go Greener, Less Risk: Access to Nature Is Associated with Lower Risk Taking in Different Domains during the COVID-19 Lockdown. Sustainability 2021, 13, 10807. https://doi.org/ $10.3390 /$ su131910807

Academic Editor: Carlos Salavera

Received: 13 July 2021

Accepted: 23 September 2021

Published: 29 September 2021

Publisher's Note: MDPI stays neutral with regard to jurisdictional claims in published maps and institutional affiliations.

Copyright: (c) 2021 by the authors. Licensee MDPI, Basel, Switzerland. This article is an open access article distributed under the terms and conditions of the Creative Commons Attribution (CC BY) license (https:/ / creativecommons.org/licenses/by/ $4.0 /)$.
1 Cognitive and Clinical Psychology Laboratory, Department of Human Sciences, European University of Rome, 00163 Rome, Italy; giuseppe.carbone@unier.it (G.A.C.); chiara.massullo@unier.it (C.M.); claudio.imperatori@unier.it (C.I.)

2 Department of Education, Roma Tre University, 00185 Rome, Italy; giuseppe.carrus@uniroma3.it

3 Department of Psychology, Sapienza University of Rome, 00185 Rome, Italy; evelina.delongis@uniroma1.it (E.D.L.); gianluca.cepale@uniroma1.it (G.C.)

4 Department of Agro-Environmental Sciences, University of Bari Aldo Moro, 70126 Bari, Italy; giovanni.sanesi@uniba.it

* Correspondence: angelo.panno@unier.it (A.P.); annalisa.theodorou@uniroma3.it (A.T.)

+ These authors share first authorship.

Abstract: Specific risk attitude and risky behavior had an important boost during the coronavirus disease 2019 (COVID-19) pandemic. In this contribution, we hypothesize that access to nature during home confinement will decrease both the tendency to passive risk taking and alcohol intake. To do so, we interviewed through an online survey two samples of Italian residents during the strict lockdown due to the first wave of the COVID-19 pandemic. Specifically, in Study 1, participants were 1519 Italian residents coming from different Italian regions, whilst in Study 2, participants were 182 students at a university of southern Italy who were monitored for one week. In Study 1, the hierarchical regression analysis attested that access to nature during the lockdown mitigated the tendency to passive risk taking, over and beyond the effect of socio-demographic variables and the psychological construct of impulsiveness, an important personality correlate of risk taking. In Study 2 , the hierarchical regression showed that access to green was associated with fewer glasses of alcohol drunk in a week of lockdown. This effect held over and above the effect of socio-demographic variables and the drinking behavior before the outbreak of the COVID-19 pandemic. In both studies, findings confirmed the beneficial effect of access to nature in specific risk-taking domains. Theoretical future directions, as well as practical implications for the management of the COVID-19 emergency by policymakers, are discussed.

Keywords: passive risk taking; alcohol intake; access to nature; COVID-19; home confinement

\section{Introduction}

For risk taking, we mean the individual conscious exposure to possible loss or injury [1]. In uncertain times, risk is a concept that cannot be avoided. The information age we live in has been characterized by maelstroms of disorienting information that may have reached a peak after the outbreak of the coronavirus disease 2019 (COVID-19) pandemic. This unexpected event, a black swan [2], contributed to raise indefiniteness and unpredictability. From the analysis of past major social adverse events such as natural disasters and economic depressions (the so-called exogenous shocks), we know that, as a consequence, individuals and the whole society undergo a state of shock [3]. The levels of psychological health decrease, negative emotions and anxiety symptoms rise, depicting, we may say, a general state of fear, learned helplessness, and pessimism [4-8]. Thus, it is not surprising that individuals during an exogenous shock exhibit more risk aversion (in 
terms of reduced investments), and this is explained by enhanced feelings of fear [9-12]. On the whole, these findings depict we may say a state of freezing caused by the stressful situation [13], which inhibits the willingness to take actions, especially risky ones.

Although, as the economic literature reports [12], the willingness to actively take risks decreases during exogenous shocks, there are specific types of risks that, on the contrary, may rise during these periods of massive distress such as the risk rising from inaction. Precisely, this type of risk arises from a state of freezing. Nevertheless, little is known about such a phenomenon. For instance, we do not know whether a state of freezing triggered by the COVID-19 outbreak can influence passive risk taking and which factors could reduce people's risk-attitude in this domain [14]. One might claim that the main feature of such a domain of risk is not acting, which shows a specific fit with norms engendered during the COVID-19 outbreak. For instance, a medical checkup represents a typical situation where is salient the probability of a contagion, thus some people might avoid doing it, even though it is relevant to reduce the probability that a bad health outcome occurs.

In the current research (Study 1), we focus on the domain of passive risk taking [14]. Passive risk taking is defined as forgoing an opportunity to act to reduce outcome variance [14]. Specifically, it refers to situations in which the perceived risk comes from not acting as compared to doing something to avoid possible harm (e.g., not wearing a seatbelt in the car). In these particular cases, for individuals undergoing an emotional state of immobility deriving from a highly improbable and unexpected event, not taking an action is a risky decision. During the outbreak of the COVID-19, postponing or avoiding medical checkups and eluding COVID-19 related preventive measures are only some of the phenomena that suggest a dangerous increase of passive risk taking during the COVID-19 pandemic (ONS, 2020).

A further type of risky behavior that may increase during social shocks might be the willingness to take unhealthy behaviors. During and after social destabilizing events such as natural disasters, economic crisis, or terrorist attacks, past research well documented a rise in such behaviors, such as smoking, recreational drugs use, and alcohol intake $[7,15,16]$. In this vein, excessive alcohol use has been considered a major public-health issue. During the COVID-19 emergency, an increase in addictive behaviors was observed too [17]. It has been proposed that, presumably, these behaviors serve as (maladaptive) coping mechanisms. In other words, the individuals experience a stressful situation and a growth of negative feelings such as boredom, frustration, anxiety, and impatience which may, in turn, promote the shift to unhealthy behavior (e.g., alcohol intake) [18-20]. Thus, in the current research (Study 2), we focus on alcohol intake for three reasons: first, it represents a use of a legal substance, thus, easily accessible during lockdowns; second, it is relatively easier to study as it is not subjected to legal repercussions, and in turn, it shows a reduced social desirability effect (especially in Italy where drinking wine at mealtimes is a rooted cultural practice); third, available data report an increment in such behavior, which is often related to other important consequences that face an increment during home confinement, such as domestic violence [21].

Since the COVID-19 emergency is not over, it is important to identify those factors that could lower both passive risk taking and alcohol intake during the COVID-19 emergency. In this contribution, we propose that one important element that can play a role in decreasing both phenomena can be access to nature. We explore the effect of access to nature during home confinement on passive risk taking (Study 1) and alcohol intake (Study 2).

\section{COVID-19 and Passive Risk Taking}

At the beginning of 2020, the outbreak of the COVID-19 pandemic has been classified as a stressful event for the global population [22]. The ills, the healthcare providers, as well as the society all, experienced a rapid shift in their habits, changing the way they see the world and acting accordingly. In this scenario, one phenomenon that was prompted by the pandemic is the increased willingness to passively take risks. One of the most surprising examples is represented by the general tendency to postpone or avoid urgent 
medical care. During the first wave of COVID-19 (March 2020) in Italy, a considerable decrement was observed in access to the emergency service [23]. This phenomenon was, in turn, associated with a disastrous increase in mortality of non-COVID-19 patients [24,25]. The decreased and delayed access to healthcare was observed later on all over the world, across different medical departments and specialist units, especially pediatrics [26-29]. An important decrement was observed also in the participation in medical screenings and checkups, in particular regarding cancer patients [30-34]. Estimates painfully predict a dramatic increase in cancer deaths in the next years because of delayed screenings [35].

Remaining within the health domain, another phenomenon related to passive risk taking observed during the pandemic was the tendency shown by some individuals to elude preventive measures related to the COVID-19, such as wearing a mask, washing hands, or using disinfectants [36]. This behavior not only signals that those individuals are risking being infected, exposing themselves to serious health consequences [36]. It also suggests the exposure to the risk of infecting other people and breaking the law, violating ethical conduct [36]. Similarly, the reluctance to be vaccinated can expose to health consequences [37]. Passive risk taking was also observed in the economic domain. For instance, examining consumer behavior during the pandemic researchers observed sharp fluctuations due to impulsive purchases, namely not reasoned buy [38].

Generally speaking, in considering taking a risk, individuals make an important evaluation of the probability of costs and benefit of the future possible choice [1]. In this process, subjectivity occupies an important place $[39,40]$. In the psychological literature, a large room has been given to the personality factors involved in risk attitude. Impulsiveness and sensation seeking were identified as important personality antecedents [41]. Other studies focused on the environmental factors involved in the willingness to take risks [42,43]. Recently, researchers seem to agree that, as a complex decision-making phenomenon, risky behavior and risk attitude are determined by a combined effect of both the individual disposition and the social environment [44]. Overall, the described scenario points out a general catastrophic heightened threshold of passive risk taking for individuals during the COVID-19 emergency, which may be especially pronounced for those already predisposed.

\section{COVID-19 and Alcohol Intake}

During the pandemic, in the general population, a serious increase was observed in the engagement in risky health behaviors, such as alcoholism [17,45]. In many countries, such as UK and Italy, a rise in the sales of alcohol was registered [21,46]. As reported by other authors [47], an increase in drinking behaviors was observed after other important social destabilizing events, such as the attack at the World Trade Center and Hurricane Katrina. These pieces of evidence showed that individuals in lockdowns craved alcohol intake as a maladaptive coping strategy, presumably as a way to calm down [48]. In the same vein, an increase in alcohol intake by some individuals during the pandemic might be induced by the need to cope with the deterioration of mental health observed in several studies [49,50].

Another important factor that may have contributed to the enhancing of alcohol intake is that this substance may have represented an accessible substitute for other addictions [51]. For instance, with the closure of those places of social gathering as pubs and clubs, enhanced controls on the streets, and the subsequent general downfall of the demand, illicit recreational drugs sales fell during lockdowns [51,52]. This may have provoked a shift for drug abusers, from recreational substances to legal addictive substances such as alcohol.

Overall, an increase in the prevalence of high-risk drinking behavior during the lockdowns was observed, depicting a concrete crisis [53]. What is more, during the outbreak of COVID-19, the health systems' response was often inadequate. Indeed, the pandemic in many cases limited the possibility to access care, excluding a large portion of those needing assistance [17]. Often treatments went online but this opportunity has been precluded for those not keeping up with technology [21]. Moreover, some preliminary studies suggest that alcohol intake may expose individuals to a higher risk of infection and 
a worse prognosis [54]. Thus, in times in which health systems may experience an overload, prevention must be considered as the first choice. Taken together, these pieces of evidence underline the need to address this concern by identifying successful tools for policymakers.

\section{The Role of Access to Nature}

After the outbreak of the COVID-19 pandemic individuals started to consider nature more essential in their lives [55-57]. Access to nature is known to have a beneficial effect on individuals' psychological health and stress [58-60], even during lockdowns [55,56,61-65]. In particular, studies conducted during the pandemic focused on two elements. First, access to the green from one's dwelling, which is the case of gardens, verandas, courtyards, and even green views. Findings attested that in time when restrictions were imposed on access to public areas, having direct access to green in their dwelling was an important factor that affected the individuals' lockdown experience $[62,63,66]$. One mechanism by which this effect is exerted might be through enhanced being away experience at home that, in turn, contributes to lower depression and anxiety [67]. Nevertheless, considering that not everyone can afford to live in proximity of nature, this line of research exposes the importance of socioeconomic inequalities in the personal response to the pandemic $[65,68]$.

Second, research demonstrated that during lockdowns individuals significantly reduced time spent outdoors, and this decrement led to higher stress and lower mental health [69]. At the same time, a growing interest in spending time in nature, especially in neighborhood parks, was registered in many countries [70]. Importantly, those who had access to public green areas during a lockdown reported higher psychological and physical health than those who had not [71]. During the pandemic period, also the permanence in parks was associated with greater positive feelings [72]. Those who reported visiting more often the urban green spaces showed greater life satisfaction and happiness, and lower feelings of loneliness, depression, and anxiety [66]. Even having a green view from one's home was associated with lower negative affect [64]. Interestingly, in a recent study, the frequency of the visit to an urban park lowered depression and anxiety symptoms through increased restorativeness and perceived social support [67].

On the whole, these studies further extend to the pandemic period the well-known effect of nature in decreasing negative psychological health-related outcomes. However, despite the flourishing proliferation of pieces of evidence in this area, no studies have been conducted so far to explore the role of greenery in important risky attitude and behavior, both before and after the outbreak of the COVID-19. In this regard, studies conducted before the outbreak of the pandemic reported the beneficial effect of green spaces in lowering future and delay discounting [73-76] and enhancing self-control [77], all important components of risk taking [78] and strictly related to behavioral addictions [73,74,79]. Regarding this latter, through its potential to reduce negative affect, nature immersion has been associated with fewer feelings of craving, an important antecedent of risky health behaviors [80]. Moreover, nature exposure has been important to prevent social isolation, a third dangerous antecedent of unhealthy behaviors, through enhanced desire for social connectedness $[79,81]$. Based on this evidence, there is reason to hypothesize the protective role of nature in lowering the willingness to take risks during home confinement.

\section{The Present Research and Overview of the Studies}

Generally speaking, data available during this pandemic emergency point to a change in the preference of risky behavior as compared to pre-COVID behavior [17,23,32]. In this study, we focus on the beneficial role of access to nature on both passive risk taking and risky health behavior, such as alcohol intake during home confinement. In particular, we hypothesized that nature, for its already documented effect on important precursors and correlates of risky decisions, would exert a role in lowering such negative outcomes [78]. Specifically, we formulate two hypotheses. First, individuals having access to green would report lower passive risk taking (Study 1). Second, we expect that for those who could access green areas during the lockdown alcohol intake would be lower (Study 2). 
To test our hypotheses, we conducted two studies in Italy during the first months of 2020 (March-May), namely in the course of the first wave of COVID-19. Italy was one of the European countries most hit by the first wave of the pandemic and where the contentment measures lasted longer [82]. In Study 1, we expect a negative relationship between access to green areas and passive risk taking. More specifically, we expect that people having access to green areas also show a reduced passive risk taking (e.g., avoiding checkups). We test our hypothesis on a heterogeneous sample, composed of Italian residents from different age groups and distributed throughout all the Italian territory. We control for important covariates possibly associated with our outcome, namely sociodemographic characteristics as gender, age, educational qualification, marital status, and smart working. As risk taking has been proved to be associated with impulsiveness [83,84], we also control for such a disposition.

In Study 2, on a sample of university students, we test the relationship between access to a garden from one's dwelling and alcohol intake. More specifically, we closely monitor the alcohol intake for one week and relate it to having or not access to a garden. Here too, we investigate the role of access to green over and above the effects of other relevant variables, namely socio-demographics as gender, age, employment, and relationship status. Given that past habits are the most important predictors of behavior [85], we controlled also for the drinking behavior before the outbreak of the COVID-19 pandemic.

\subsection{Study 1}

In this study, we investigate the association between access to green areas and passive risk taking on a relatively large sample of Italian residents drawn from the general population. We control for important covariates possibly associated with our outcome, namely sociodemographic characteristics as gender, age, educational qualification, marital status, and smart working, as well as impulsiveness.

\subsubsection{Method}

Participants and procedures. As a part of a larger project aimed at investigating COVID-19 related attitudes and behaviors [86], an online questionnaire with variables of interest was shared with Italian residents through personal contacts and social media (e.g., Facebook, LinkedIn, Instagram, and WhatsApp) during the first wave of the pandemic (March-May 2020). After being assured of both anonymity and the voluntary nature of their involvement, informed consent was collected from all participants. A community sample of 1519 agreed to voluntarily take part in the study. Age ranged from 18 to $74(\mathrm{M}=28.49, \mathrm{SD}=10.89)$. As can be seen from Table 1 , the majority of participants were women. The geographical origin of participants was relatively balanced across Italian regions. Regarding educational qualifications, almost all participants held at least a high school diploma. Most of participants were unmarried and not smart working.

Measures. The individual tendency for passive risk taking was assessed using the Italian version of the passive risk-taking measure [14,87], composed of 25 items adapted for the present study. Specifically, we asked participants to imagine themselves in each of the scenarios described in the items, directly referring to the current pandemic emergency. The items assess the tendency to taking (or not) an action to decrease risk in three domains, namely resources (e.g., "Buy an expensive product (computer, refrigerator) only after comparing prices in several stores"), health (e.g., "Immediately go to the doctor's when something in my body is aching or bothering me"), and ethics (e.g., "Always wear a seatbelt when sitting in the back seat"). Responses range from 1 (very unlikely) to 7 (very likely). Responses are recoded so that higher scores reflect higher levels of passive risk taking. In this study, we use the total scores, and Cronbach's alpha was $0.76(\mathrm{M}=88.36, \mathrm{SD}=17.94)$. 
Table 1. Sociodemographic characteristics of the sample (Study 1).

\begin{tabular}{|c|c|}
\hline Variables & $\%$ \\
\hline \multicolumn{2}{|l|}{ Gender } \\
\hline Men & 24 \\
\hline Women & 76 \\
\hline \multicolumn{2}{|l|}{ Geographical origin } \\
\hline Northern regions & 34 \\
\hline Central regions & 42 \\
\hline Southern regions & 24 \\
\hline \multicolumn{2}{|l|}{ Educational qualification } \\
\hline Junior high school diploma & 3 \\
\hline High school diploma & 51 \\
\hline Bachelor's degree or higher qualification & 46 \\
\hline \multicolumn{2}{|l|}{ Marital status } \\
\hline Unmarried & 76 \\
\hline Married & 24 \\
\hline \multicolumn{2}{|l|}{ Smart working } \\
\hline No & 62 \\
\hline Yes & 38 \\
\hline
\end{tabular}

Impulsiveness was measured using the Italian validation of the I7 impulsivenessventuresomeness-empathy Scale $[88,89]$. Specifically, for the current study, the 19 dichotomous items (yes/no) of the impulsivity subscale were used (e.g., "Do you often buy things on impulse?"). The instructions were adapted for this study, specifically asking participants to refer to the pandemic period while answering. Cronbach's alpha was $0.79(\mathrm{M}=6.62$, $\mathrm{SD}=3.86$ ).

Lastly, to investigate people's access to nature, we asked participants if, during their home confinement, they had access to green areas (i.e., if they could visit them), with the following item: "Did you have access to a green area and visit it during this period?". Specifically, this was a dichotomous item, indicating whether or not participants had access to any kind of green areas (i.e., public and/or private). Approximately, half of the sample had access to green areas $(49 \%)$.

Statistical analyses. All analyses were performed using the SPSS 25.0 statistical package [90]. Missing values were deleted listwise. To investigate the relationships among variables of interest, we first computed the zero-order correlations. Next, to test our hypothesis, we carried out a hierarchical multiple regression analysis in two steps with passive risk taking as the outcome. In the first step, we included all the sociodemographic variables, namely gender, age, educational qualification, marital status, and smart working. In the second step, we added access to green areas and impulsiveness. The associations were reported as unstandardized (B) and standardized ( $\beta$ ) coefficients and their $p$-values. The 0.05 level of significance was adopted throughout all analyses.

\subsubsection{Results}

The correlations between the variables of interest are reported in Table 2. As can be seen, having access to green was negatively and significantly associated with passive risk taking. Passive risk taking was, in turn, positively and significantly associated with impulsiveness, and negatively and significantly associated with age and marital status. Impulsiveness was higher for women and was negatively and significantly associated with age, educational qualification, marital status, and smart working. 
Table 2. Correlations among variables of interest (Study 1).

\begin{tabular}{|c|c|c|c|c|c|c|c|c|}
\hline & (1) & (2) & (3) & (4) & (5) & (6) & (7) & (8) \\
\hline (1) Access to green areas & - & & & & & & & \\
\hline (2) Passive risk taking & $-0.09 * *$ & - & & & & & & \\
\hline (3) Impulsiveness & -0.01 & $0.20^{* * *}$ & - & & & & & \\
\hline (4) Gender & 0.01 & -0.5 & $0.05 *$ & - & & & & \\
\hline (5) Age & 0.02 & -0.06 * & $-0.14^{* * *}$ & $-0.14^{* * *}$ & - & & & \\
\hline (6) Educational qualification & -0.01 & 0.04 & $-0.14^{* * *}$ & 0.04 & $0.21^{* * *}$ & - & & \\
\hline (7) Marital status & -0.01 & $-0.06 *$ & $-0.06 *$ & -0.04 & $0.55^{* * *}$ & $0.06 *$ & - & \\
\hline (8) Smart working & 0.02 & -0.02 & $-0.07^{* *}$ & $-0.05 *$ & $0.07^{* *}$ & $0.15^{* * * *}$ & 0.03 & - \\
\hline
\end{tabular}

Note. Gender: 1 = men, 2 = women. Educational qualification: $1=$ junior high school diploma, $2=$ high school diploma, $3=$ bachelor's degree or higher qualification. Marital status: $0=$ unmarried, $1=$ married. Smart working: $0=$ no, $1=$ yes. Access to green areas: $0=$ no, $1=$ yes. ${ }^{*} p<0.05,{ }^{* *} p<0.01,{ }^{* * *} p<0.001$.

Results of the hierarchical multiple regression analysis are shown in Table 3. As can be seen, both the models were explaining a significant portion of the variance. In the first step, there was a negative and significant effect of gender, indicating lower passive risk taking for women. No other significant associations were found (all $p>0.07$, see Table 3 second column). In the second step, the effect of access to green was negative and significant, meaning that having access to green was associated with lower passive risk taking. Importantly, this effect was significant over and beyond the effect of impulsiveness, which is positive and significant (see Table 3 second column). The $\Delta \mathrm{R}^{2}$ was significant, attesting that the second model explained an additional $4 \%$ of the variance.

Table 3. Results of the hierarchical multiple regression with passive risk taking as the outcome (Study $1 ; \mathrm{N}=1485)$.

\begin{tabular}{|c|c|c|c|c|c|c|c|c|c|c|}
\hline & \multicolumn{5}{|c|}{ Step 1} & \multicolumn{5}{|c|}{ Step 2} \\
\hline & B & SE & B $[95 \% \mathrm{CI}]$ & $\beta$ & $p$ & B & SE & B $[95 \% \mathrm{CI}]$ & $\beta$ & $p$ \\
\hline Gender & -2.40 & 1.09 & {$[-4.50,-0.20]$} & -0.06 & 0.032 & -2.63 & 1.07 & {$[-4.73,-0.53]$} & -0.06 & 0.014 \\
\hline Age & -0.09 & 0.05 & {$[-0.19,0.02]$} & -0.05 & 0.107 & -0.04 & 0.05 & {$[-0.15,0.06]$} & -0.03 & 0.412 \\
\hline Educational qualification & 1.60 & 0.87 & {$[-0.11,3.30]$} & 0.05 & 0.067 & 2.27 & 0.86 & {$[0.59,3.95]$} & 0.07 & 0.008 \\
\hline Marital status & -1.93 & 1.30 & {$[-4.48,0.61]$} & -0.05 & 0.136 & -2.15 & 1.27 & {$[-4.63,0.34]$} & -0.05 & 0.091 \\
\hline Smart working & -1.25 & 0.96 & {$[-3.13,0.64]$} & -0.03 & 0.196 & -0.84 & 0.94 & {$[-2.69,1.01]$} & -0.02 & 0.373 \\
\hline Impulsiveness & - & - & - & - & - & 0.89 & 0.12 & {$[0.66,1.13]$} & 0.19 & $<0.001$ \\
\hline Access to green areas & - & - & - & - & - & -3.08 & 0.90 & {$[-4.85,-1.31]$} & -0.09 & $<0.001$ \\
\hline $\mathrm{R}_{\text {adj }}^{2}$ & & & & & $0.01 * *$ & & & & & $0.05^{* * *}$ \\
\hline $\mathrm{R}^{2}$ & & & & & $0.01 * *$ & & & & & $0.06^{* * *}$ \\
\hline$\Delta \mathrm{R}^{2}$ & & & & & & & & & & $0.04^{* * *}$ \\
\hline
\end{tabular}

Note. Gender: 1 = men, 2 = women. Educational qualification: 1 = junior high school diploma, 2 = high school diploma, $3=$ bachelor's degree or higher qualification. Marital status: $0=$ unmarried, $1=$ married. Smart working: $0=$ no, $1=$ yes. Access to green areas: $0=$ no, $1=$ yes. $B=$ unstandardized regression coefficient. $S E=$ standard error. $C I=$ confidence intervals. $R_{\text {adj }}^{2}=$ adjusted $R^{2}$. Bold values indicate significant effects. ${ }^{* *} p<0.01,{ }^{* * *} p<0.001$.

\subsubsection{Discussion}

In this study, the hypothesis that having access to green areas during home confinement is associated with passive risk taking was confirmed. This effect was significant over and beyond the effect of what has been demonstrated as an important predictor of risk taking, namely impulsiveness [83,84]. Unsurprisingly, for women, passive risk taking was lower than for men. This result is in line with past research that has shown how women, because of higher state anxiety experienced in risky decisions, are less prone than men to take risks [91]. We believe that this study has an advantage, namely the large sample size and the heterogeneity of participants (i.e., broad age range and large distribution across the Italian regions), thus increasing findings generalizability. One limitation of the study is related to the data collection method used. Some groups might be missing or underrepresented, such as elderly persons not being familiar with digital devices. Moreover, further studies could investigate the role of the frequency and length of visits to green areas on passive risk taking. Next, in Study 2, we focus on a specific risky behavior in the domain 
of health (i.e., alcohol intake). It represents a typical unhealthy behavior that people may use to cope with stressful situations (e.g., COVID-19 outbreak) or the boredom triggered by lockdown restrictions, and furthermore, it is not subject to legal restrictions. Thus, in Study 2, we seek to point out a potential factor (i.e., access to a garden) that might reduce the alcohol intake.

\subsection{Study 2}

In this study, we test the association between access to a garden from one's dwelling and alcohol intake in a sample of university students spending their home confinement in Italy. To do so, we measure participants' alcohol intake each day for one week and focus on the differences in weekly means. We also use as covariates gender, age, employment, relationship status, and the drinking behavior before the COVID-19 outbreak.

\subsubsection{Method}

Participants and procedures. As part of a larger project, 182 students at an Italian university situated in southern Italy agreed to take part in the study voluntarily and were interviewed online at the end of March 2020, namely during the strict national lockdown in Italy due to the first wave of COVID-19. Students' anonymity was ensured, and they received extra credits for participating. First of all, participants filled out a questionnaire asking about their personal experience before the COVID-19 outbreak and information about their home confinement. The following week, every evening for 7 days we measured our dependent variable, namely alcohol intake.

Age ranged from 19 to $35(\mathrm{M}=23.54, \mathrm{SD}=2.43)$. Regarding the composition of the sample, descriptive statistics are reported in Table 4. The majority of the sample was women and reported spending their home confinement in the southern regions of Italy and being nonworking students. More than half of the participants reported being in a relationship.

Table 4. Sociodemographic characteristics of the sample (Study 2).

\begin{tabular}{lcc}
\hline & Variables & $\%$ \\
\hline Gender & Men & 27 \\
& Women & 73 \\
\hline Geographical origin & Northern regions & 8 \\
& Central regions & 10 \\
& Southern regions & 82 \\
\hline Employment status & Nonworking student & \\
& $\quad$ Working student & 81 \\
& & 19 \\
\hline Relationship status & Single & 35 \\
& Engaged in a relationship & 57 \\
& Cohabiting with the partner & 7 \\
& Married & 1 \\
\hline
\end{tabular}

Measures. Every evening, participants were asked about the number of glasses of alcohol drunk during that day. Then, we aggregated the data per week. Thus, this variable corresponds to the average of glasses drunk during the week of reference $(M=0.36$, $\mathrm{SD}=0.67)$. To assess the drinking behavior before the COVID-19 outbreak we used one item [92] "I did not drink, or never drank more than one or two glasses of wine or beer per day" with responses " $1=$ true", " $2=$ not entirely true", and " $3=$ false" $(\mathrm{M}=1.39, \mathrm{SD}=0.68)$. Therefore, higher scores indicate a less healthy lifestyle before the outbreak of the pandemic. Lastly, 
to investigate participants' access to a garden from their dwellings, we asked if they had access to their own garden during home confinement with the following item: "Did you have access to a garden from your dwelling during this period?". Specifically, this was a dichotomous item, indicating whether or not participants had access to a garden from their dwellings. Just under half of the total sample had access to a garden from their dwellings (42\%).

Statistical analyses. All analyses were performed using the SPSS 25.0 statistical package [90]. Missing values were deleted listwise. To investigate the relationships among variables of interest, we first computed the zero-order correlations. Next, to test our hypothesis, we carried out a hierarchical multiple regression model in two steps with the number of glasses of alcohol (weekly average) as the outcome. In the first step, we included all the sociodemographic characteristics, namely gender, age, relationship status, and employment. In the second step, we added access to a garden from one's dwelling and drinking behavior before the outbreak of the Covid-19 pandemic. The associations were reported as unstandardized (B) and standardized $(\beta)$ coefficients and their $p$-values. The 0.05 level of significance was adopted throughout all analyses.

\subsubsection{Results}

The correlation matrix with the variables of interest is reported in Table 5. Having access to a garden was negatively and significantly associated with alcohol intake. Alcohol intake was positively and significantly associated with drinking behavior before COVID-19 and was significantly lower for women. Moreover, drinking behavior before COVID-19 was significantly lower for women and people in a relationship or married.

Table 5. Correlations among variables of interest (Study 2).

\begin{tabular}{|c|c|c|c|c|c|c|c|}
\hline & (1) & (2) & (3) & (4) & (5) & (6) & (7) \\
\hline (1) Access to a garden & - & & & & & & \\
\hline (2) Glasses of alcohol drunk (weekly average) & -0.18 * & - & & & & & \\
\hline (3) Drinking behavior before COVID-19 & -0.06 & $0.36^{* * *}$ & - & & & & \\
\hline (4) Gender & 0.01 & $-0.30^{* * *}$ & $-0.18^{*}$ & - & & & \\
\hline (5) Age & $-0.16^{*}$ & 0.16 * & 0.06 & $-0.16^{*}$ & - & & \\
\hline (6) Relationship status & 0.01 & 0.14 & $-0.16^{*}$ & 0.05 & 0.16 * & - & \\
\hline (7) Employment & 0.02 & 0.02 & -0.08 & -0.12 & $0.28^{* * *}$ & 0.04 & - \\
\hline
\end{tabular}

Note. Gender: $1=$ men, $2=$ women. Employment: $0=$ nonworking student, $1=$ working student. Relationship status: $1=$ single, $2=$ engaged in a relationship, $3=$ cohabiting with the partner, $4=$ married. Access to a garden from one's dwelling: $0=$ no, $1=$ yes. ${ }^{*} p<0.05,{ }^{* * *} p<0.001$.

Results of the hierarchical multiple regression analysis attested that both models were explaining a significant portion of the variance of the outcome (see Table 6). In the first step, there was a significant negative effect of gender, indicating that women reported lower alcohol intake over the week of reference. All the other effects were non-significant (all $p>0.09$, see Table 6 column 1 ). In the second step, the effect of access to a garden from one's dwelling was negative and significant, revealing that those that reported having access to a garden showed lower alcohol intake over the week of reference. This effect was significant over and above the effect of drinking behavior before the outbreak of the COVID-19 pandemic, which was positive and significant (see Table 6 second column). The $\Delta \mathrm{R}^{2}$ was significant, attesting an additional $15 \%$ of the variance explained by the second model. 
Table 6. Results of the hierarchical multiple regression with number of glasses of alcohol drunk (weekly average) as the outcome (Study 2; N = 169).

\begin{tabular}{|c|c|c|c|c|c|c|c|c|c|c|}
\hline & \multicolumn{5}{|c|}{ Step 1} & \multicolumn{5}{|c|}{ Step 2} \\
\hline & B & SE & B $[95 \%$ CI $]$ & $\beta$ & $p$ & B & SE & B $[95 \%$ CI $]$ & $\beta$ & $p$ \\
\hline Gender & -0.49 & 0.11 & {$[-0.70,-0.27]$} & -0.34 & $<0.000$ & -0.41 & 0.10 & {$[-0.61,-0.21]$} & -0.28 & $<0.000$ \\
\hline Age & 0.01 & 0.02 & {$[-0.04,0.05]$} & 0.02 & 0.763 & -0.01 & 0.02 & {$[-0.05,0.03]$} & -0.04 & 0.604 \\
\hline Relationship status & 0.13 & 0.08 & {$[-0.02,0.29]$} & 0.13 & 0.092 & 0.19 & 0.07 & {$[0.05,0.33]$} & 0.18 & 0.008 \\
\hline Employment & -0.12 & 0.12 & {$[-0.37,0.12]$} & -0.08 & 0.317 & -0.04 & 0.11 & {$[-26,0.19]$} & -0.02 & 0.744 \\
\hline $\begin{array}{l}\text { Drinking behavior before } \\
\text { COVID-19 }\end{array}$ & - & - & - & - & - & 0.32 & 0.06 & {$[0.19,0.45]$} & 0.35 & $<0.000$ \\
\hline Access to a garden & - & - & - & - & - & -0.23 & 0.09 & {$[-0.40,-0.05]$} & -0.18 & 0.011 \\
\hline $\mathrm{R}^{2}$ adj & & & & & $0.11^{* * *}$ & & & & & $0.25 * * *$ \\
\hline $\mathrm{R}^{2}$ & & & & & $0.13^{* * *}$ & & & & & $0.27^{* * *}$ \\
\hline$\Delta \mathrm{R}^{2}$ & & & & & & & & & & $0.15^{* * *}$ \\
\hline
\end{tabular}

Note. Gender: 1 = men; 2 = women. Employment: $0=$ nonworking student, 1 = working student. Relationship status: $1=$ single, $2=$ engaged in a relationship, $3=$ cohabiting with the partner, $4=$ married. Access to a garden from one's dwelling: $0=$ no, $1=$ yes. $\mathrm{B}=$ unstandardized regression coefficient. $\mathrm{SE}=$ standard error. $\mathrm{CI}=$ confidence intervals. $\mathrm{R}^{2}$ adj $=$ adjusted $\mathrm{R}^{2}$. Bold values indicate significant effects. ${ }^{* *} p<0.01,{ }^{* * *} p<0.001$.

\subsubsection{Discussion}

In this study, our hypothesis that having access to green areas from one's dwelling was associated with lower alcohol intake in a week of strict lockdown was confirmed. Importantly, this result was significant over and beyond the drinking behavior before the COVID-19 outbreak. Regarding the other covariates, in line with the literature, women reported a smaller number of glasses of alcohol drunk [93].

On the whole, the main advantage of this study is the measurement of the dependent variable. Indeed, we closely monitored alcohol intake for one week of lockdown. Importantly, such a report of behavior collected every day constitutes a more accurate measure of real behavior than a retrospective questionnaire [94]. Second, the focus on access to a garden in one's dwelling proved that green is important during lockdowns, confirming its beneficial role in lowering drinking behavior. It was argued that a period when access to public parks was extremely limited represents a special opportunity for investigating green home spaces [61]. However, these benefits are limited to individuals that can afford a house with an outdoor space, which can be especially challenging for high-density cities and more needy individuals [68]. One limitation of this study is that we interviewed a non-representative sample of students at a university of southern Italy. Thus, more heterogeneous samples (i.e., different age ranges and different Italian regions) and higher sample sizes should be used to further investigate access to nature and alcohol intake and improve generalizability. Next, we discuss the potential implications of these results for policies.

\section{General Discussion}

Starting from the first months of 2020 and till the moment we are writing, the majority of the world population is experiencing containment measures that limit their freedom and largely involve a profound adjustment of individual lives. The large availability of data collected during the pandemic reveals the massive changes in people's attitudes and behavior across different domains. Accordingly, as evidenced by numerous phenomena, during home confinement, the preference for certain risky behavior changed as compared to pre-pandemic levels. In particular, the tendency for passive risk taking and risky health behaviors rose alarmingly. In this scenario, relevant for adjusting the response of policymakers is identifying those factors that could prevent the spreading of these detrimental attitudes and behaviors. In this research, we proposed that access to nature during home confinement should lower the inclination for passive risk taking and risky health behavior, such as alcohol intake. To test our predictions, we carried out two studies on two samples of individuals spending their home confinement in Italy during the first wave of COVID-19. 


\section{Strengths and Limitations}

Across the two studies, our hypotheses were confirmed. Indeed, access to green was associated with a lower tendency to passive risk taking (Study 1), as well as alcohol intake (Study 2). These effects were significant over and beyond the effects of potential confounding factors, namely socio-demographic variables, relevant dispositions, and individual past habits. Importantly, findings from the two studies are congruent and suggest that access to green could play an important role in preventing or lowering risky behavior during home confinement. We believe that the novelty of our study lies in two features. First, little attention was deserved to the effect of nature on risky attitudes and behaviors [79]. Although there is little evidence on the role of greenery on behavioral addictions, no studies have investigated so far, its relationship with passive risk taking. Second, we investigate this effect during a relevant societal emergency as the COVID-19 pandemic. Our results are in line with evidence on how access to indoor and outdoor green areas during lockdowns supports positive individual outcomes [61,95]. With the exception that our study is the first so far, to the best of our knowledge, to have focused on the positive role that access to green areas may have on risky behavior during home confinement.

Despite the strengths, this research has some limitations that should be acknowledged. Firstly, the correlational nature of both studies does not allow us to establish causal relationships, although they are suggested from past research. Nevertheless, our results provide relevant insights on the relationships between contact with nature and risk taking in its forms of passive risk taking and alcohol intake. Thus, we believe that, given the importance to investigate these relationships, quasi-experimental and longitudinal studies should be designed to shed light on causality, as well as on the dynamic mechanisms underlying such relationships. Secondly, in both studies, we used self-report measures. In particular, future studies may want to investigate passive risk taking through experimental (i.e., observational) paradigms. Nonetheless, such results offer relevant insights to stimulate future research in this direction and shed light on the positive role that contact with nature may have in reducing risky behavior.

\section{Theoretical Implications}

All in all, our findings suggest that access to nature lowers passive risk taking and alcohol intake during lockdowns. However, why is it so? We may speculate that nature has a beneficial role in antecedents of both passive risk taking and risky behavior. One of which can be delay discounting, namely seeing remote outcomes as less valuable than immediate outcomes $[14,96,97]$. The second one may be emotion regulation, namely the management of negative as well as positive emotions $[37,84,98,99]$. Interestingly, although delay discounting and emotion regulation can be framed as individual tendencies, they are both negatively affected by stressful situations susceptible to the restorativeness effect of exposure to nature (e.g., the pandemic) $[22,100,101]$. Indeed, nature has been found to intervene on both delay discounting [75] and emotion regulation [59,95], as well as stress [60]. Future studies may investigate the role of these as well as other potential mediators through which nature may intervene to counteract risky behavior both during home confinement and through normal daily life.

For instance, a potential mechanism by which nature can influence higher order cognitive processes (e.g., decision making) might be its capacity to restore cognitive resources that we know to be related to decision making under conditions of risk. Indeed, some authors point out the role of nature in restoring cognitive resources and others highlight the effect of cognitive resources in decision-making processes [102,103]. Thus, a link between exposure to nature and decision making under conditions of risk through cognitive resources might be plausible. A further link by which contact with nature might influence risk taking is its capacity to repair negative mood. Based on the mood maintenance hypothesis (MMH) [104], postulating that people in negative mood make riskier choices to obtain greater potential rewards in the hope of repairing their negative mood, one can argue that the contact with nature might represent a positive coping strategy aimed at 
repairing negative mood that replaces maladaptive coping strategies, such as alcohol intake and others. The potential routes linking the contact with nature to higher order cognitive processes (e.g., risky decision making) can be varied. Thus, the overarching message of the current research consists in stimulating future studies in this direction in order to explore such mechanisms and, in turn, supporting applied interventions aimed at addressing such phenomena that are considered public health issues.

We focused on passive risk-taking attitudes during the pandemic. This construct is different from active risk taking. Studies demonstrated that it is an independent factor that has different antecedents, but it is not less dangerous [14]. Indeed, we mentioned lower access to care, the avoidance of medical screenings, and the reluctance to be vaccinated as possible undesirable correlates of passive risk taking. However, we do not exclude that more factors could be involved in assessing the risk in those situations. For instance, in the case of medical care, one additional element that could intervene in the decision-making process can be the fear of being infected [105]. Thus, in this case, a consideration of both active risk taking (exposing oneself to an environment with a higher circulation of the virus, such as the hospital) and passive risk taking (delayed or missed care) can lead to the outcome (i.e., access to medical care). The tendency to attribute lower personal responsibility in passive rather than active risk taking may lead to choosing the latter over the former [106]. Future studies are needed both to explore more closely the process that leads to passive risk taking, as well as to investigate which is the role played by nature in this phenomenon. The key role of nature might be insightful to tailor applied interventions aimed at reducing passive risk taking, especially during home confinement due to a global pandemic.

Lastly, the effects of other variables that have been proved to enhance or diminish the beneficial effect of nature in other circumstances (e.g., studies on the effects of nature on well-being and restorativeness) should be investigated in relation to risk taking during the pandemic. For instance, some personal tendencies are involved in the ability to recognize the value of greenery as well as in risky behavior (e.g., the habitual use of cognitive reappraisal) $[107,108]$, and accordingly, such individual differences need to be investigated when studying the relationship between nature and risky behavior. In conclusion, this line of research is relatively unexplored and in expansion. More attention should be paid to extending the already known beneficial effects of nature in other domains, on risky behavior, especially during the pandemic.

\section{Implications for Social Policies in the Era of COVID-19 Pandemic}

Whereas further evidence is needed to support our findings, these may be extremely relevant for the environmental science. Ensuring access to public green areas from the population during strict lockdown and periods with lighter containment measures, as well as single individuals in quarantine, should decrease the willingness to take risks. Spending time in nature represents a healthy pastime that may help individuals fill the day and cope with lockdowns. To this aim, future studies may consider also other activities in green areas, such as gardening and physical exercise [65]. Greater emphasis could be put on the opening of these areas during lockdowns, developing strict codes and regimentation in line with international containment indications. To this aim, rearrangements for those spaces should be also considered.

Urban areas and their utilization changed profoundly during the pandemic. As highlighted by a recent article [70], we could predict that these aspects will persist even when the emergency will be over. Thus, actions directed to restructure public green areas should be undertaken in light of this profound transformation. Central will be comprehending such modifications, especially in terms of the expectations and behaviors of users. In particular, on the one hand, the authors refer to the renewed interest in neighborhood parks for many people. One research attested that the harsher the containment measures the higher the visits to urban green areas [109]. In this regard, as compared to other countries and studies [56], Italians showed the strongest interest in visiting urban parks during 
the first wave of the pandemic. These findings are remarkable if we think that, often, access to public green areas was discouraged by governments and local authorities during this period.

On the other hand, however, they warn us of the altered relationship with green spaces that some individuals, especially the youngest ones, may experience after a prolonged time spent indoors. This may have caused a psychological distance from these places, modifying also the feelings associated with them created by past experiences [70]. Considering the increasing number of findings on the beneficial role of access to these areas during lockdowns, including ours, we believe that such an issue needs to be addressed through tailored policies. To ensure a psychological attachment to public green areas, changes could be made for allowing their utilization safely. For instance, in parks, new areas could be devoted to individualized use and more space could be designed for guaranteeing individual exercise [70].

\section{Conclusions}

In conclusion, facing the COVID-19 emergency has not been easy for anyone. Not only the pandemic itself but also its consequences contributed to building a climate of uncertainty, fear, stress, loneliness, and grief. Taken together, these feelings have enhanced the tendency for passive risk taking as well as a reliance on risky health behaviors as maladaptive coping strategies (e.g., alcohol intake). A historical moment such as this needs historical actions to efficiently contrast the increasing spread of behavioral addictions [86,110]. Many related the outbreak of the COVID-19 pandemic to the progressive destruction of the environment by humans [111]. In this regard, we believe that studies such as ours point to revaluating nature as the answer. Policymakers should carefully consider resorting to public green as a suitable instrument for buffering the negative consequences caused by the COVID-19 pandemic.

Author Contributions: Conceptualization, A.P.; methodology, A.P. and A.T.; formal analysis, A.T.; investigation, A.T., G.A.C., E.D.L., C.M., G.C. (Gianluca Cepale), C.I. and G.S.; resources, A.T., G.A.C. and E.D.L.; data curation, A.T., G.A.C., E.D.L., C.M., G.C. (Gianluca Cepale) and C.I.; writing—original draft preparation, A.T. and A.P.; writing—review and editing, A.T., G.C. (Giuseppe Carrus), G.A.C., E.D.L., C.M., G.C. (Gianluca Cepale), C.I. and G.S.; supervision, A.P.; project administration, A.P. and A.T.; funding acquisition, A.P., G.C. (Giuseppe Carrus) and G.S. All authors have read and agreed to the published version of the manuscript.

Funding: This work was carried out under the project "Establishing Urban FORest based solutions In Changing Cities (EUFORICC)" and financially supported by the Ministry of Education, University and Research (MIUR) of Italy (PRIN 20173RRN2S).

Institutional Review Board Statement: The study was conducted according to the guidelines of the Declaration of Helsinki, and approved by the Ethics Committee of the European University of Rome (Prot. N. 004/20).

Informed Consent Statement: Informed consent was obtained from all subjects involved in the study.

Data Availability Statement: The raw data supporting the conclusions of this article will be made available by the authors upon request without undue reservation.

Conflicts of Interest: The authors declare no conflict of interest.

\section{References}

1. Kaplan, S.; Garrick, B.J. On The Quantitative Definition of Risk. Risk Anal. 1981, 1, 11-27. [CrossRef]

2. Taleb, N.N. The Black Swan: The Impact of the Highly Improbable; Random House: Allen Lane, UK, 2007.

3. Klein, N. The Shock Doctrine: The Rise of Disaster Capitalism; Macmillan: New York, NY, USA, 2007.

4. El-Zoghby, S.M.; Soltan, E.M.; Salama, H.M. Impact of the COVID-19 Pandemic on Mental Health and Social Support among Adult Egyptians. J. Community Health 2020, 45, 689-695. [CrossRef]

5. Lifshin, U.; Mikulincer, M.; Kretchner, M. Motivated helplessness in the context of the COVID-19 pandemic: Evidence for a curvilinear relationship between perceived ability to avoid the virus and anxiety. J. Soc. Clin. Psychol. 2020, 39, 479-497. [CrossRef] 
6. Morgul, E.; Bener, A.; Atak, M.; Akyel, S.; Aktaş, S.; Bhugra, D.; Ventriglio, A.; Jordan, T.R. COVID-19 pandemic and psychological fatigue in Turkey. Int. J. Soc. Psychiatry 2020, 6, 128. [CrossRef] [PubMed]

7. Mucci, N.; Giorgi, G.; Roncaioli, M.; Perez, J.F.; Arcangeli, G. The correlation between stress and economic crisis: A systematic review. Neuropsychiatr. Dis. Treat. 2016, 12, 983-993. [CrossRef]

8. Seligman, M.E. Learned helplessness. Annu. Rev. Med. 1972, 23, 407-412. [CrossRef]

9. Guiso, L.; Sapienza, P.; Zingales, L. Time varying risk aversion. J. Financ. Econ. 2018, 128, 403-421. [CrossRef]

10. Loewenstein, G. Preferences, behavior, and welfare: Emotions in economic theory and economic behavior. Am. Econ. Rev. 2000, 90, 426-432. [CrossRef]

11. Malmendier, U.; Nagel, S. Depression Babies: Do Macroeconomic Experiences Affect Risk Taking? Q. J. Econ. 2011, 126, 373-416. [CrossRef]

12. Rizvi, S.K.A.; Mirza, N.; Naqvi, B.; Rahat, B. Covid-19 and asset management in EU: A preliminary assessment of performance and investment styles. J. Asset Manag. 2020, 21, 281-291. [CrossRef]

13. Schmidt, N.B.; Richey, J.A.; Zvolensky, M.J.; Maner, J.K. Exploring human freeze responses to a threat stressor. J. Behav. Ther. Exp. Psychiatry 2008, 39, 292-304. [CrossRef] [PubMed]

14. Keinan, R.; Bereby-Meyer, Y. "Leaving it to chance"-Passive risk taking in everyday life. Judgm. Decis. Mak. 2012, 7, 705-715.

15. Lanctot, J.Q.; Stockton, M.B.; Mzayek, F.; Read, M.; McDevitt-Murphy, M.; Ward, K. Effects of disasters on smoking and relapse: An exploratory study of hurricane katrina victims. Am. J. Health Educ. 2008, 39, 91-94. [CrossRef]

16. Vlahov, D.; Galea, S.; Ahern, J.; Resnick, H.; Kilpatrick, D. Sustained Increased Consumption of Cigarettes, Alcohol, and Marijuana among Manhattan Residents after September 11, 2001. Am. J. Public Health 2004, 94, 253-254. [CrossRef]

17. Mallet, J.; Dubertret, C.; Le Strat, Y. Addictions in the COVID-19 era: Current evidence, future perspectives a comprehensive review. Prog. Neuro-Psychopharmacol. Biol. Psychiatry 2021, 106. [CrossRef]

18. Brooks, S.K.; Webster, R.K.; Smith, L.E.; Woodland, L.; Wessely, S.; Greenberg, N.; Rubin, G.J. The psychological impact of quarantine and how to reduce it: Rapid review of the evidence. Lancet 2020, 395, 912-920. [CrossRef]

19. Carrus, G.; Panno, A.; Deiana, L.; Crano, W.D.; Fiorentino, D.; Ceccanti, M.; Mareri, A.R.; Bonifazi, A.; Giuliani, A. Group Membership and Adolescents' Alcohol Intake: The Role of Drinking Motives. J. Stud. Alcohol Drugs 2016, 77, 143-149. [CrossRef]

20. Cherikh, F.; Frey, S.; Bel, C.; Attanasi, G.; Alifano, M.; Iannelli, A. Behavioral Food Addiction During Lockdown: Time for Awareness, Time to Prepare the Aftermath. Obes. Surg. 2020, 30, 3585-3587. [CrossRef]

21. Finlay, I.; Gilmore, I. Covid-19 and alcohol-A dangerous cocktail. BMJ 2020, 369, m1987. [CrossRef]

22. Cooke, J.E.; Eirich, R.; Racine, N.; Madigan, S. Prevalence of posttraumatic and general psychological stress during COVID-19: A rapid review and meta-analysis. Psychiatry Res. 2020, 292, 113347. [CrossRef]

23. Tartari, F.; Guglielmo, A.; Fuligni, F.; Pileri, A. Changes in emergency service access after spread of COVID-19 across Italy. J. Eur. Acad. Dermatol. Venereol. 2020, 34. [CrossRef]

24. Odone, A.; Delmonte, D.; Gaetti, G.; Signorelli, C. Doubled mortality rate during the COVID-19 pandemic in Italy: Quantifying what is not captured by surveillance. Public Health 2021, 190, 108-115. [CrossRef]

25. Santi, L.; Golinelli, D.; Tampieri, A.; Farina, G.; Greco, M.; Rosa, S.; Beleffi, M.; Biavati, B.; Campinoti, F.; Guerrini, S.; et al. Non-COVID-19 patients in times of pandemic: Emergency department visits, hospitalizations and cause-specific mortality in Northern Italy. PLoS ONE 2021, 16, e0248995. [CrossRef]

26. Aguiar de Sousa, D.; Sandset, E.C.; Elkind, M.S.V. The Curious Case of the Missing Strokes During the COVID-19 Pandemic. Stroke 2020, 51, 1921-1923. [CrossRef]

27. Birkmeyer, J.D.; Barnato, A.; Birkmeyer, N.; Bessler, R.; Skinner, J. The impact of the COVID-19 pandemic on hospital admissions in the United States. Health Aff. 2020, 39, 2010-2017. [CrossRef]

28. Mehrotra, A.; Chernew, M.; Linetsky, D.; Hatch, H.; Cutler, D.; Schneider, E.C. The Impact of COVID-19 on Outpatient Visits in 2020: Visits Remained Stable, Despite a Late Surge in Cases. Available online: https://www.commonwealthfund.org/ publications / 2021/feb/impact-covid-19-outpatient-visits-2020-visits-stable-despite-late-surge (accessed on 30 April 2021).

29. Solis, E.; Hameed, A.; Brown, K.; Pleass, H.; Johnston, E. Delayed emergency surgical presentation: Impact of corona virus disease (COVID-19) on non-COVID patients. ANZ J. Surg. 2020, 90, 1482-1483. [CrossRef]

30. De Vincentiis, L.; Carr, R.A.; Mariani, M.P.; Ferrara, G. Cancer diagnostic rates during the 2020 'lockdown', due to COVID-19 pandemic, compared with the 2018-2019: An audit study from cellular pathology. J. Clin. Pathol. 2021, 74, 187-189. [CrossRef]

31. Earnshaw, C.H.; Hunter, H.J.A.; McMullen, E.; Griffiths, C.E.M.; Warren, R.B. Reduction in skin cancer diagnosis, and overall cancer referrals, during the COVID-19 pandemic. Br. J. Dermatol. 2020, 183, 792-794. [CrossRef]

32. ONS Rapporto Sullla Ripartenza Degli Screening—Settembre 2020. Available online: https: / /www.osservatorionazionalescreening. it/content/rapporto-sulla-ripartenza-degli-screening-settembre-2020\# (accessed on 30 April 2021).

33. Trehan, A.; Jain, R.; Bansal, D. Oncology care in a lower middle-income country during the COVID-19 pandemic. Pediatr. Blood Cancer 2020, 67. [CrossRef]

34. Vanni, G.; Materazzo, M.; Pellicciaro, M.; Ingallinella, S.; Rho, M.; Santori, F.; Cotesta, M.; Caspi, J.; Makarova, A.; Pistolese, C.A.; et al. Breast Cancer and COVID-19: The Effect of Fear on Patients' Decision-making Process. In Vivo 2020, 34, 1651-1659. [CrossRef]

35. Sharpless, N.E. COVID-19 and cancer. Science 2020, 368, 1290. [CrossRef] 
36. Keinan, R.; Idan, T.; Bereby-Meyer, Y. Compliance with COVID-19 prevention guidelines: Active vs. passive risk takers. Judgm. Decis. Mak. 2021, 16, 20-35.

37. Chou, W.-Y.S.; Budenz, A. Considering Emotion in COVID-19 Vaccine Communication: Addressing Vaccine Hesitancy and Fostering Vaccine Confidence. Health Commun. 2020, 35, 1718-1722. [CrossRef] [PubMed]

38. Ahmed, R.R.; Streimikiene, D.; Rolle, J.-A.; Duc, P.A. The COVID-19 Pandemic and the Antecedants for the Impulse Buying Behavior of US Citizens. J. Compet. 2020, 12, 5-27. [CrossRef]

39. Barnett, J.; Breakwell, G.M. Risk perception and experience: Hazard personality profiles and individual differences. Risk Anal. 2001, 21, 171-178. [CrossRef] [PubMed]

40. Lopes, L.L. Between Hope and Fear: The Psychology of Risk. Adv. Exp. Soc. Psychol. 1987, 20, $255-295$.

41. Lauriola, M.; Panno, A.; Levin, I.P.; Lejuez, C.W. Individual Differences in Risky Decision Making: A Meta-analysis of Sensation Seeking and Impulsivity with the Balloon Analogue Risk Task. J. Behav. Decis. Mak. 2014, 27, 20-36. [CrossRef]

42. Hill, E.M.; Jenkins, J.; Farmer, L. Family unpredictability, future discounting, and risk taking. J. Socio. Econ. 2008, 37, 1381-1396. [CrossRef]

43. Lewis, C.E.; Lewis, M.A. Peer pressure and risk-taking behaviors in children. Am. J. Public Health 1984, 74, 580-584. [CrossRef]

44. Breakwell, G.M. The Psychology of Risk; Cambridge University Press: Cambridge, UK, 2014.

45. Koopmann, A.; Georgiadou, E.; Kiefer, F.; Hillemacher, T. Did the General Population in Germany Drink More Alcohol during the COVID-19 Pandemic Lockdown? Alcohol Alcohol. 2020, 55, 698-699. [CrossRef]

46. IWSR. Covid-19 Market Impact Snapshot Report; London, UK. 2020. Available online: https://www.theiwsr.com/iwsr-covid-19 -impact-report-portfolio/ (accessed on 20 September 2021).

47. Chodkiewicz, J.; Talarowska, M.; Miniszewska, J.; Nawrocka, N.; Bilinski, P. Alcohol consumption reported during the COVID-19 pandemic: The initial stage. Int. J. Environ. Res. Public Health 2020, 17, 4677. [CrossRef]

48. Bollen, Z.; Pabst, A.; Creupelandt, C.; Fontesse, S.; Lannoy, S.; Pinon, N.; Maurage, P. Prior drinking motives predict alcohol consumption during the COVID-19 lockdown: A cross-sectional online survey among Belgian college students. Addict. Behav. 2021, 115, 106772. [CrossRef]

49. Olszewska-Guizzo, A.; Fogel, A.; Escoffier, N.; Ho, R. Effects of COVID-19-related stay-at-home order on neuropsychophysiological response to urban spaces: Beneficial role of exposure to nature? J. Environ. Psychol. 2021, 75, 101590. [CrossRef]

50. Wang, C.; Chudzicka-Czupała, A.; Grabowski, D.; Pan, R.; Adamus, K.; Wan, X.; Hetnał, M.; Tan, Y.; Olszewska-Guizzo, A.; Xu, L.; et al. The Association Between Physical and Mental Health and Face Mask Use During the COVID-19 Pandemic: A Comparison of Two Countries With Different Views and Practices. Front. Psychiatry 2020, 11. [CrossRef]

51. Sinclair, D.L.; Vanderplasschen, W.; Savahl, S.; Florence, M.; Best, D.; Sussman, S. Substitute addictions in the context of the COVID-19 pandemic. J. Behav. Addict. 2020. [CrossRef]

52. Bergeron, A.; Décary-Hétu, D.; Giommoni, L. Preliminary findings of the impact of COVID-19 on drugs crypto markets. Int. J. Drug Policy 2020, 83, 102870. [CrossRef]

53. Jackson, S.E.; Garnett, C.; Shahab, L.; Oldham, M.; Brown, J. Association of the COVID-19 lockdown with smoking, drinking and attempts to quit in England: An analysis of 2019-20 data. Addiction 2020, 116, 1233. [CrossRef]

54. Testino, G.; Pellicano, R. Alcohol consumption in the COVID-19 era. Minerva Gastroenterol. Dietol. 2020, 66. [CrossRef]

55. Grima, N.; Corcoran, W.; Hill-James, C.; Langton, B.; Sommer, H.; Fisher, B. The importance of urban natural areas and urban ecosystem services during the COVID- 19 pandemic. PLoS ONE 2020, 15, e0243344. [CrossRef]

56. Ugolini, F.; Massetti, L.; Calaza-Martínez, P.; Cariñanos, P.; Dobbs, C.; Ostoic, S.K.; Marin, A.M.; Pearlmutter, D.; Saaroni, H.; Šaulienè, I.; et al. Effects of the COVID-19 pandemic on the use and perceptions of urban green space: An international exploratory study. Urban For. Urban Green. 2020, 56, 126888. [CrossRef]

57. Venter, Z.S.; Barton, D.N.; Gundersen, V.; Figari, H.; Nowell, M. Urban nature in a time of crisis: Recreational use of green space increases during the COVID-19 outbreak in Oslo, Norway. Environ. Res. Lett. 2020, 15, 104075. [CrossRef]

58. Bowler, D.E.; Buyung-Ali, L.M.; Knight, T.M.; Pullin, A.S. A systematic review of evidence for the added benefits to health of exposure to natural environments. BMC Public Health 2010, 10, 456. [CrossRef]

59. McMahan, E.A.; Estes, D. The effect of contact with natural environments on positive and negative affect: A meta-analysis. J. Posit. Psychol. 2015, 10, 507-519. [CrossRef]

60. Twohig-Bennett, C.; Jones, A. The health benefits of the great outdoors: A systematic review and meta-analysis of greenspace exposure and health outcomes. Environ. Res. 2018, 166, 628-637. [CrossRef]

61. Pérez-Urrestarazu, L.; Kaltsidi, M.P.; Nektarios, P.A.; Markakis, G.; Loges, V.; Perini, K.; Fernández-Cañero, R. Particularities of having plants at home during the confinement due to the COVID-19 pandemic. Urban For. Urban Green. 2020. [CrossRef]

62. Peters, T.; Halleran, A. How our homes impact our health: Using a COVID-19 informed approach to examine urban apartment housing. Emerald. Com. 2020. [CrossRef]

63. Pouso, S.; Borja, Á.; Fleming, L.E.; Gómez-Baggethun, E.; White, M.P.; Uyarra, M.C. Contact with blue-green spaces during the COVID-19 pandemic lockdown beneficial for mental health. Sci. Total Environ. 2020. [CrossRef]

64. Spano, G.; D’Este, M.; Giannico, V.; Elia, M.; Cassibba, R.; Lafortezza, R.; Sanesi, G. Association between indoor-outdoor green features and psychological health during the COVID-19 lockdown in Italy: A cross-sectional nationwide study. Urban For. Urban Green. 2021, 62, 127156. [CrossRef] 
65. Theodorou, A.; Panno, A.; Carrus, G.; Carbone, G.A.; Massullo, C.; Imperatori, C. Stay home, stay safe, stay green: The role of gardening activities on mental health during the Covid-19 home confinement. Urban For. Urban Green. 2021, 61, 127091. [CrossRef]

66. Soga, M.; Evans, M.J.; Tsuchiya, K.; Fukano, Y. A room with a green view: The importance of nearby nature for mental health during the COVID-19 pandemic. Ecol. Appl. 2021, 31. [CrossRef]

67. Dzhambov, A.M.; Lercher, P.; Browning, M.H.E.M.; Stoyanov, D.; Petrova, N.; Novakov, S.; Dimitrova, D.D. Does greenery experienced indoors and outdoors provide an escape and support mental health during the COVID-19 quarantine? Environ. Res. 2020, 110420. [CrossRef]

68. Li, X.; Zhang, C.; Li, W.; Kuzovkina, Y.A.; Weiner, D. Who lives in greener neighborhoods? The distribution of street greenery and its association with residents' socioeconomic conditions in Hartford, Connecticut, USA. Urban For. Urban Green. 2015, 14, 751-759. [CrossRef]

69. Cindrich, S.L.; Lansing, J.E.; Brower, C.S.; McDowell, C.P.; Herring, M.P.; Meyer, J.D. Associations Between Change in Outside Time Pre- and Post-COVID-19 Public Health Restrictions and Mental Health: Brief Research Report. Front. Public Health 2021, 9. [CrossRef]

70. Honey-Rosés, J.; Anguelovski, I.; Chireh, V.K.; Daher, C.; Konijnendijk van den Bosch, C.; Litt, J.S.; Mawani, V.; McCall, M.K.; Orellana, A.; Oscilowicz, E.; et al. The impact of COVID-19 on public space: An early review of the emerging questions-Design, perceptions and inequities. Cities Health 2020, 1-17. [CrossRef]

71. Xie, J.; Luo, S.; Furuya, K.; Sun, D. Urban Parks as Green Buffers During the COVID-19 Pandemic. Sustainability $2020,12,6751$. [CrossRef]

72. Zhu, J.; Xu, C. Sina microblog sentiment in Beijing city parks as measure of demand for urban green space during the COVID-19. Urban For. Urban Green. 2021, 58, 126913. [CrossRef]

73. Berry, M.S.; Sweeney, M.M.; Morath, J.; Odum, A.L.; Jordan, K.E. The nature of impulsivity: Visual exposure to natural environments decreases impulsive decision-making in a delay discounting task. PLoS ONE 2014, 9, e97915. [CrossRef]

74. Berry, M.S.; Repke, M.A.; Nickerson, N.P.; Conway, L.G.; Odum, A.L.; Jordan, K.E. Making Time for Nature: Visual Exposure to Natural Environments Lengthens Subjective Time Perception and Reduces Impulsivity. PLoS ONE 2015, 10, e0141030. [CrossRef]

75. Repke, M.A.; Berry, M.S.; Conway, L.G.; Metcalf, A.; Hensen, R.M.; Phelan, C. How does nature exposure make people healthier?: Evidence for the role of impulsivity and expanded space perception. PLoS ONE 2018, 13, e0202246. [CrossRef]

76. Van der Wal, A.J.; Schade, H.M.; Krabbendam, L.; van Vugt, M. Do natural landscapes reduce future discounting in humans? Proc. R. Soc. B Biol. Sci. 2013, 280. [CrossRef]

77. Taylor, A.F.; Kuo, F.E.; Sullivan, W.C. Coping with ADD. The surprising connection to green play settings. Environ. Behav. 2001, 33, 54-77. [CrossRef]

78. Berry, M.S.; Repke, M.A.; Metcalf, A.L.; Jordan, K.E. Promoting Healthy Decision-Making via Natural Environment Exposure: Initial Evidence and Future Directions. Front. Psychol. 2020, 11. [CrossRef]

79. Berry, M.S.; Rung, J.M.; Crawford, M.C.; Yurasek, A.M.; Ferreiro, A.V.; Almog, S. Using greenspace and nature exposure as an adjunctive treatment for opioid and substance use disorders: Preliminary evidence and potential mechanisms. Behav. Processes 2021, 186, 104344. [CrossRef] [PubMed]

80. Martin, L.; Pahl, S.; White, M.P.; May, J. Natural environments and craving: The mediating role of negative affect. Health Place 2019, 58, 102160. [CrossRef]

81. Weinstein, N.; Przybylski, A.K.; Ryan, R.M. Can Nature Make Us More Caring? Effects of Immersion in Nature on Intrinsic Aspirations and Generosity. Personal. Soc. Psychol. Bull. 2009, 35, 1315-1329. [CrossRef] [PubMed]

82. Wikipedia COVID-19 lockdowns. Available online: https://en.wikipedia.org/wiki/COVID-19_lockdowns (accessed on 16 February 2021).

83. Baumann, A.A.; Odum, A.L. Impulsivity, risk taking, and timing. Behav. Processes 2012, 90, 408-414. [CrossRef] [PubMed]

84. Panno, A.; Sarrionandia, A.; Lauriola, M.; Giacomantonio, M. Alexithymia and risk preferences: Predicting risk behaviour across decision domains. Int. J. Psychol. 2019, 54, 468-477. [CrossRef]

85. Ouellette, J.A.; Wood, W. Habit and Intention in Everyday Life: The Multiple Processes by Which Past Behavior Predicts Future Behavior. Psychol. Bull. 1998, 124, 54-74. [CrossRef]

86. Panno, A.; Carbone, G.A.; Massullo, C.; Farina, B.; Imperatori, C. COVID-19 Related Distress Is Associated With Alcohol Problems, Social Media and Food Addiction Symptoms: Insights From the Italian Experience During the Lockdown. Front. Psychiatry 2020, 11. [CrossRef] [PubMed]

87. Riva, S.; Gorini, A.; Cutica, I.; Mazzocco, K.; Pravettoni, G. Translation, cross-cultural adaptation, and reliability, of the Italian version of the passive risk taking (PRT) scale. Judgm. Decis. Mak. 2015, 10, 597-604.

88. Eysenck, S.B.G.; Pearson, P.R.; Easting, G.; Allsopp, J.F. Age norms for impulsiveness, venturesomeness and empathy in adults. Pers. Individ. Dif. 1985, 6, 613-619. [CrossRef]

89. Russo, P.M.; Leone, L.; De Pascalis, V. Cross-cultural validity of the I7 impulsiveness-venturesomeness-empathy scales: Evidence from the Italian I7. Compr. Psychiatry 2011, 52, 446-452. [CrossRef]

90. IBM Corp. Released IBM SPSS Statistics for Windows; Version 25.0; IBM Corp.: Armonk, NY, USA, 2017.

91. Panno, A.; Donati, M.A.; Milioni, M.; Chiesi, F.; Primi, C. Why Women Take Fewer Risk Than Men Do: The Mediating Role of State Anxiety. Sex Roles 2018, 78, 286-294. [CrossRef] 
92. Theodorou, A.; Violani, C.; Alessandri, G. Living without a job: Positivity and psychophysical health in a sample of unemployed workers. G. Ital. Psicol. 2017, 44, 993-1003. [CrossRef]

93. Wilsnack, R.W.; Wilsnack, S.C.; Kristjanson, A.F.; Vogeltanz-Holm, N.D.; Gmel, G. Gender and alcohol consumption: Patterns from the multinational GENACIS project. Addiction 2009, 104, 1487-1500. [CrossRef] [PubMed]

94. Ellison, W.D.; Trahan, A.C.; Pinzon, J.C.; Gillespie, M.E.; Simmons, L.M.; King, K.Y. For whom, and for what, is experience sampling more accurate than retrospective report? Pers. Individ. Dif. 2020, 163, 110071. [CrossRef]

95. Lades, L.K.; Laffan, K.; Daly, M.; Delaney, L. Daily emotional well-being during the COVID-19 pandemic. Br. J. Health Psychol. 2020, 25, 902-911. [CrossRef]

96. Odum, A.L. Delay discounting: I'm ak, you're ak. J. Exp. Anal. Behav. 2011, 96, 427-439. [CrossRef]

97. Reynolds, B. A review of delay-discounting research with humans: Relations to drug use and gambling. Behav. Pharmacol. 2006, 17, 651-667. [CrossRef]

98. Panno, A.; Donati, M.A.; Chiesi, F.; Primi, C. Trait Emotional Intelligence is related to risk-taking through negative mood and anticipated fear. Soc. Psychol. 2015, 46, 361-367. [CrossRef]

99. Weiss, N.H.; Sullivan, T.P.; Tull, M.T. Explicating the role of emotion dysregulation in risky behaviors: A review and synthesis of the literature with directions for future research and clinical practice. Curr. Opin. Psychol. 2015, 3, 22-29. [CrossRef]

100. Fields, S.A.; Lange, K.; Ramos, A.; Thamotharan, S.; Rassu, F. The relationship between stress and delay discounting: A metaanalytic review. Behav. Pharmacol. 2014, 25, 434-444. [CrossRef]

101. Seligowski, A.V.; Lee, D.J.; Bardeen, J.R.; Orcutt, H.K. Emotion Regulation and Posttraumatic Stress Symptoms: A Meta-Analysis. Cogn. Behav. Ther. 2015, 44, 87-102. [CrossRef]

102. Giacomantonio, M.; Jordan, J.; Fennis, B.M.; Panno, A. When the motivational consequences of ego depletion collide: Conservation dominates over reward-seeking. J. Exp. Soc. Psychol. 2014, 55, 217-220. [CrossRef]

103. Panno, A.; Carrus, G.; Lafortezza, R.; Mariani, L.; Sanesi, G. Nature-based solutions to promote human resilience and wellbeing in cities during increasingly hot summers. Environ. Res. 2017, 159, 249-256. [CrossRef]

104. Isen, A.M.; Patrick, R. The effect of positive feelings on risk taking: When the chips are down. Organ. Behav. Hum. Perform. 1983, 31, 194-202. [CrossRef]

105. Lazzerini, M.; Barbi, E.; Apicella, A.; Marchetti, F.; Cardinale, F.; Trobia, G. Delayed access or provision of care in Italy resulting from fear of COVID-19. Lancet Child Adolesc. Health 2020, 4, e10-e11. [CrossRef]

106. Keinan, R.; Bereby-Meyer, Y. Perceptions of Active Versus Passive Risks, and the Effect of Personal Responsibility. Personal. Soc. Psychol. Bull. 2017, 43, 999-1007. [CrossRef]

107. Panno, A.; Carrus, G.; Maricchiolo, F.; Mannetti, L. Cognitive reappraisal and pro-environmental behavior: The role of global climate change perception. Eur. J. Soc. Psychol. 2015, 45, 858-867. [CrossRef]

108. Panno, A.; Theodorou, A.; Carrus, G.; Imperatori, C.; Spano, G.; Sanesi, G. Nature reappraisers, benefits for the environment: A model linking cognitive reappraisal, the "being away" dimension of restorativeness and eco-friendly behavior. Front. Psychol. 2020, 11. [CrossRef] [PubMed]

109. Geng, D.C.; Innes, J.; Wu, W.; Wang, G. Impacts of COVID-19 pandemic on urban park visitation: A global analysis. J. For. Res. 2021, 32, 553-567. [CrossRef]

110. Spagnolo, P.A.; Montemitro, C.; Leggio, L. New challenges in addiction medicine: COVID-19 infection in patients with alcohol and substance use disorders-The perfect storm. Am. J. Psychiatry 2020, 177, 805-807. [CrossRef] [PubMed]

111. Carrington, D. Coronavirus: 'Nature is Sending Us a Message', Says UN Environment Chief. Available online: https://www. theguardian.com/world/2020/mar/25/coronavirus-nature-is-sending-us-a-message-says-un-environment-chief (accessed on 30 April 2021). 